Relatorio

\title{
A PERDA DA DIVERSIDADE LINGUIISTICA NO MUNDO E OS PROCESOS DE HOMOXENEIZACIÓN LINGÜISTICA *
}

M. Carme Junyent

Universitat de Barcelona 

Se temos en conta as informacións de varias fontes, podemos facer o cálculo aproximado de que, ao longo dos últimos cinco séculos, a humanidade perdeu a metade do patrimonio lingüístico co que contaba antes das grandes expansións colonizadoras. Dado o efecto multiplicador dos procesos de substitución lingüística, esta perda continuada levounos a unha situación límite na que unha parte moi pequena da humanidade é falante de moitas linguas, mentres que soamente un pequeno número de linguas ten unha gran cantidade de falantes. Este contraste só se pode reverter coa revitalización e recuperación de espazos de uso de moitas linguas que se atopan en proceso de substitución.

A comunidade científica ten a responsabilidade de dar a coñecer as implicacións da morte das linguas: a perda de coñecemento útil para a humanidade nos ámbitos máis diversos -alimentación, saúde, matemáticas, filosofía, etc.- e a suplantación dun patrimonio cultivado polas comunidades desde as súas orixes por un produto desvinculado da historia e da capacidade creativa dos pobos. As persoas deben poder ter acceso a este coñecemento para que as súas actitudes e o seu comportamento lingüísticos poidan ser responsables e consecuentes fronte á perda de diversidade lingüística.

A UNESCO alertou sobre esta perda e as súas consecuencias e fixo varias recomendacións para deter e reverter o proceso de homoxeneización lingüística no mundo. Pero a consideración da perda da diversidade lingüística como un problema grave para a humanidade espertou moi recentemente. Non obstante, o fenómeno da morte das linguas seguramente é tan antigo como a existencia da fala humana e do contacto entre as linguas, como lembran Janse e Tol:

Con todo, mesmo unha ollada rápida ao número de linguas indoeuropeas e afroasiáticas desaparecidas debería abondar para ter unha idea do alcance da morte de linguas en tempos antigos. Entre elas cóntanse diversas linguas literarias importantes como o acadio, o ugarítico, o hebreo antigo, o arameo antigo, o exipcio antigo e os dialectos anti- 
gos do grego. Outras son menos coñecidas, como as seguintes da familia lingüística indoeuropea: parto, sogdiano, coresmio, cotanés, saca e tumsuqués (iranio medio), luvio, palaico, licio, lidio, cario, sidético e pisidio (anatolio), falisco, osco, umbro, peligno, marrucino, vestino, véneto e picenio do sur (itálico), galo, lepóntico e celtíbero (celta), tracio e dacio, ilirio e mesapico, frixio, macedonio antigo, e outras. Todas estas linguas coñécense a partir de testemuños escritos, pero de moitas outras linguas desaparecidas só se coñece o nome, e probablemente haxa moitas máis que non se sabe nin se saberá nunca que existiron (Janse e Tol, 2003, introdución de Janse, p. XI).

A diferenza cos procesos do pasado é, con todo, a velocidade e a cantidade na que se dan actualmente. $\mathrm{O}$ alcance dos procesos de substitución lingüística -non hai ningún lugar no mundo onde non se estea a restrinxir a diversidade lingüística- e as consecuencias que teñen estes procesos, non só para as comunidades implicadas directamente senón para toda a humanidade, espertaron a conciencia de que cómpre facer algo para parar o proceso e revitalizar as linguas que están a ser abandonadas polos seus falantes. A comunidade científica, e moi especialmente os lingüistas, tardaron moito en decatárense das implicacións deste fenómeno. Agás os traballos pioneiros de Joseph Vendryes, ata os anos sesenta - cando Joshua Fishman comeza a ocuparse dos aspectos sociais- e os setenta -cando Nancy Dorian describe os aspectos lingüísticos da morte das linguas- a Lingüística non toma os procesos de substitución das linguas como obxecto de investigación ata convertelos na actualidade en motivo de preocupación e, asemade, en obxecto de investigación preferente.

A morte dunha lingua non significa unicamente a perda dun sistema de comunicación ou dunha parte do patrimonio inmaterial da humanidade, é un proceso devastador no que unha comunidade, empurrada por circunstancias diversas pero sempre insoportables, abandona o uso da súa lingua e pasa a empregar outra, que pode ser a de uso máis frecuente no seu ámbito, a oficial do seu país ou calquera outra que poida exercer unha presión suficiente como para conseguir substituír a propia da comunidade. Pero a morte dunha lingua é tamén un proceso individual no que unha persoa, un membro dunha comunidade implicada nun proceso de substitución, corta o vínculo máis íntimo cos seus devanceiros e coa súa historia. $\mathrm{O}$ desarraigamento por substitución lingüística, que adoita comportar un desexo de mellora, paradoxalmente, acaba con 
frecuencia na marxinación de individuos que, ao renunciaren á súa historia, se atopan sen pasado e sen futuro e sen saberen cal é o seu lugar no mundo. Varios especialistas que investigaron procesos de substitución lingüística falan destes efectos devastadores alén da perda de patrimonio cultural. Fishman, por exemplo, manifestaba que:

O que se perde cando desaparece unha lingua, especialmente a curto prazo, é a integración sociocultural das xeracións, a cohesión, a naturalidade e a creatividade silenciosa, o sentimento de identidade seguro, mesmo sen conciencia política ningunha de identidade, o sentimento de valía colectiva dunha comunidade e dun pobo [...]. Pola perda destas características págase un prezo no aumento dos niveis de marxinación, en danos tanto á saúde física como mental de dúas ou máis xeracións, no enorme incremento da incidencia de trastornos sociais manifestados en forma de delitos civís e penais, e no aumento do gasto público destinado a eliminar ou reducir estes trastornos -moitos dos cales acabaron por constituír a armazón da vida moderna. Por último, o que se perde é a creatividade cultural -nas cancións, na narrativa, no teatro, no imaxinario, na danza e nas ferramentas, e tamén nas artes figurativas- que, a longo prazo, enriquece non só o ámbito inmediato na lingua orixinal senón tamén o conxunto da experiencia humana a través de milleiros de traducións. Pódese sobrevivir á perda de todo o antedito pero, en moitos aspectos, a consecuencia desa perda é unha diminución grave da calidade de vida, incluído o propio sentido da vida. Está nas mans das linguas e culturas máis ameazadas concienciarnos máis a todos sobre este problema, pero é responsabilidade das linguas máis grandes e seguras abordar dun xeito construtivo e magnánimo este problema universal no ámbito da ecoloxía humana e cultural (Fishman, 1994, p. 60-61).

\section{Sarah G. Thomason falaba en termos parecidos:}

A morte de linguas é tan triste como o seu nome, é unha perda culturalmente devastadora para todas e cada unha das comunidades lingüísticas cuxa lingua morre e tamén unha perda para a comunidade académica. Cada perda dunha lingua prívanos dunha fiestra á mente humana e ao espírito humano; cada lingua que morre prívanos dun receptáculo único de experiencias e pensamentos humanos. A perda dunha lingua priva a súa comunidade de moito máis, porque unha boa parte da súa cultura desaparece irre- 
mediablemente coa lingua. A morte de linguas non é un fenómeno moderno -os anais da historia están cheos de nomes e, en ocasións, testemuños deste problema-, pero os índices actuais de perda de linguas son alarmantemente elevados e motivo de preocupación para os lingüistas e os falantes de linguas ameazadas (Thomason, 2002, p. 223).

Son moitos os autores que se referiron ás consecuencias, pero, para entendermos as proporcións do problema ao que nos enfrontamos, non nos abonda cos efectos devastadores da perda de diversidade lingüística, nin tampouco coa análise e comprensión de procesos concretos. Como mínimo, é necesaria unha perspectiva histórica e global, porque máis importante que o número de linguas que se falan actualmente é saber que, desde que Colón chegou a América e empezaron as grandes colonizacións, o número de linguas existentes se reduciu á metade e a situación de moitas comunidades lingüísticas leva a pensar que, ao longo deste século, poden desaparecer entre o 50 e o $95 \%$ das faladas na actualidade. Os feitos que avalan esta previsión son que, actualmente, máis dun 10\% das linguas que aínda se falan só teñen xa derradeiros falantes, un 40\% xa interromperon a transmisión interxeracional e outro $40 \%$ son linguas que mostran síntomas de proceso de substitución pero que non están aínda en fase irreversible. Esta situación límite só se pode explicar polos efectos multiplicadores dos procesos de substitución lingüística, porque o cambio de lingua non lle afecta só á comunidade implicada senón a toda a súa rede de relacións. Así, se dúas comunidades A e B estiveron en contacto historicamente, quer polo coñecemento mutuo das linguas respectivas, quer porque unha delas coñece a lingua da outra, cando a comunidade $A$ abandona a súa primeira lingua e adopta a outra, a comunidade $\mathrm{B}$ vese obrigada a aprender a nova lingua se quere manter o contacto. Dado que as comunidades adoitan ter contacto con comunidades varias, a difusión da lingua dominante esténdese a través da rede e vai ocupando novos ámbitos de uso a partir dos que se pode iniciar o proceso de bilingüismo das comunidades, imprescindible para que se dea a substitución lingüística.

Este efecto multiplicador foi tamén a causa da profundísima alteración do equilibrio ecolingüístico que actualmente xa é un feito e que ten todo o comportamento dunha enfermidade autoinmune, en tanto que a dinámica que se xerou ataca o propio organismo. Este fenómeno pódese ilustrar con algúns 
datos: se no mundo se falan unhas cinco mil linguas e hai seis mil millóns de habitantes, a media de falantes por lingua é dun millón douscentos mil; pero o feito é que hai poucas linguas con moitos millóns de falantes e moitas linguas con poucos falantes. De modo xeral, poderiamos afirmar que o $95 \%$ da humanidade fala o $5 \%$ das linguas e que o $5 \%$ da humanidade fala o $95 \%$ das linguas. $\mathrm{E}$, de feito, se temos en conta que o número de linguas con máis de dez millóns de falantes non chega ao centenar e que as linguas con máis dun millón de falantes son unhas trescentas, é obvio que estas trescentas linguas déixanlles moi poucos falantes ao resto, feito que dificulta aínda máis a súa supervivencia. Lee e McLaughlin resumen esta situación así:

Das entre tres mil e oito mil linguas diferentes que existen no mundo, en función de como se conten, só trescentas poden considerarse «linguas poderosas» e, xa que logo, teñen garantía, sorprendentemente, de sobrevivir ata o século XXII. O resto das linguas e pobos dependen directamente de formas de produción que, ao actuar no nome dos grupos máis favorecidos, xeran e estenden explotación, marxinación, contaminación urbana e industrial e a desaparición de culturas e linguas (Lee e McLaughlin, 2001, p. 24).

O escaso número de falantes foi utilizado acotío para facer predicións sobre o futuro das linguas. Krauss (Krauss, 1992), por exemplo, pon o millón de falantes como límite para considerar que unha lingua está ameazada, pero é obvio que este non pode ser un criterio universal. En primeiro lugar, polo gran número de linguas que se manteñen en parte grazas ao feito de que a comunidade permanece estable no tocante ao número de membros. En segundo lugar, pola propia existencia de linguas con moito menos dun millón de falantes, por exemplo o islandés, que non mostran signos de obsolescencia. Finalmente, por outro argumento que non podemos ignorar: hai linguas con máis de dez millóns de falantes -ou que os tiveron ata hai poucos anos- que están a reducir de maneira clara esta cifra; sirvan como exemplo o curdo, a lingua amaziga, o quechua, que, malia non estaren abocadas á extinción inmediata, se atopan nun proceso clarísimo de redución do número de falantes, por represión política, por actitudes lingüísticas negativas ou por emigracións que, ao decimar o número de persoas no lugar de orixe, restrinxen aínda máis as posibilidades de uso. Se os números absolutos non se poden empregar sempre como indicadores, a UNES- 
CO proporcionou outra cifra que permite facer predicións máis precisas: unha lingua pode considerarse ameazada cando a transmisión interxeracional no seo da comunidade é inferior ao 30\%. E Harald Haarmann (Haarmann, 1986) toma en consideración como variables etnodemográficas que a comunidade lingüística teña menos de mil falantes, que a área de asentamento da comunidade sexa moi dispersa, que a comunidade lingüística se atope na diáspora en grupos illados, que a maioría dos falantes viva en zonas urbanas, ou que a comunidade lingüística se caracterice por grandes emigracións por mor das condicións laborais. Daquela, os factores demográficos son relevantes cando se combinan con outros que implican cambios na relación co territorio ou cos demais membros da comunidade.

Se nos fixamos na situación xeográfica dos procesos de substitución lingüística, podemos observar, en xeral, que as zonas onde se concentran máis linguas con derradeiros falantes son Australia, Siberia, Canadá e os Estados Unidos de América. No continente americano, nos lugares mencionados, o futuro non é moi esperanzador, segundo sinalan Lee e McLaughlin:

Abonda con ver a situación dos grupos amerindios para comprobar o alcance do caos. Das aproximadamente cincocentas linguas e culturas aborixes de Norteamérica, menos de vinte están caracterizadas por algo menos grave que a desaparición inminente. En Alasca, onde dúas xeracións atrás había unhas vinte e tres linguas nativas, estímase que só tres sobrevivirán na próxima década, e está previsto que só unha sobrevivirá ata a próxima xeración (Krauss, 1992). No tocante ao navagho, que é unha das linguas e culturas indíxenas americanas máis saudables en moitos aspectos, a lingua e modos de vida diné corren un grave perigo. $\mathrm{O}$ cambio do navagho ao inglés, racionalizado en moitos ámbitos pola maldita supervivencia do máis apto do darwinismo cultural, como explicaremos máis adiante, está a producirse a unha velocidade asombrosa (Lee e McLaughlin, 2001, p. 24).

No resto do continente hai unha gran diversidade de casos que mostran un avance da situación, desde o Caribe -primeira zona de contacto cos colonizadores-, onde xa non se fala lingua amerindia ningunha; pola costa atlántica cara ao sur, onde o proceso de homoxeneización está moi preto da culminación -en Uruguai xa ocorre o mesmo que no Caribe-; e cara á costa do Pacífico, onde o 
proceso non está tan adiantado. Inevitablemente, as zonas de acceso máis difícil -a selva e as montañas- son os lugares onde se preserva máis a diversidade lingüística, ameazada, con todo, por cada desprazamento forzado das comunidades, quer por ocupacións do seu territorio, quer pola emigración. E, en tempos máis recentes, debido á expansión dos medios de comunicación, que, lonxe de convertérense no medio de expresión das comunidades, serven de órgano difusor das culturas dominantes. A zona do Pacífico, onde atopamos lugares cun alto índice de diversidade lingüística, como Vanatu ou Papúa-Nova Guinea, é tamén o lugar do mundo no que se están a dar máis procesos de substitución lingüística, e onde á devastación lingüística de Australia se lle poden engadir procesos de substitución lingüística máis ou menos adiantados, desde as linguas kanak de Nova Caledonia, ás de Papúa-Nova Guinea, etc.

Este proceso xeneralizado de homoxeneización lingüística nos territorios mencionados ata o de agora ten como linguas dominantes o inglés, o castelán e, xa a moita distancia, o francés e mais o ruso. Pero a deriva toma outro aspecto en Asia, onde ata a primeira metade do século XX, e fóra de territorios específicos como é o caso de Siberia, non se detectaba un proceso tan xeneralizado. Nos últimos decenios, así e todo, a investigación en curso mostra que se están a dar procesos de substitución na China, Thailandia, Nepal, India, Indonesia e Irán, entre outros. O que caracteriza a maior parte destes procesos é que a lingua que substitúe ás que se atopan en perigo de extinción é a oficial do Estado, que, paradoxalmente e como consecuencia de ser máis próxima cás linguas "globais», penetra máis facilmente na vida cotiá das poboacións implicadas. A esta proximidade lingüístico-cultural engádeselle a facilidade crecente de comunicación e desprazamento, feito que altera claramente a relación entre a lingua e o territorio e contribúe, xa que logo, á multiplicación dos procesos e á súa conseguinte aceleración.

Xunto con Asia, África aparece aínda como a gran reserva da diversidade lingüística, en tanto que a porcentaxe dos procesos de substitución que se dan non é tan alta como nos demais continentes e a interrupción da transmisión interxeracional non está tan adiantada. Gerritt Dimmendaal describe así esta situación:

Curiosamente, o cambio de lingua e o proceso de morte de linguas asociado a este teñen unha menor incidencia no continente africano ca na maioría das demais partes do 
mundo. Un dos motivos que explican isto probablemente sexa o feito de que as linguas oficiais ou nacionais de moitos dos actuais Estados africanos, como o inglés, o francés ou o portugués, dominan menos a vida cotiá das persoas que noutros lugares, polo que deixan espazo para o desenvolvemento de modelos de multilingüismo estables, no canto de xerar situacións de diglosia (Dimmendaal, 1998, p. 71).

Sobra dicir que isto non é o resultado de accións encamiñadas á preservación da diversidade lingüística do continente, senón máis ben da incapacidade das potencias coloniais de difundiren as súas linguas ao conxunto da poboación nos casos en que esta fora a pretensión. Porque cando se optou por unha lingua africana como a oficial os resultados tamén foron devastadores. No caso de Tanzania, cunha lingua máis accesible ao conxunto da poboación, como é o suahili, como lingua oficial, Batibo fai este retrato:

Por outra banda, as linguas autóctonas están a ser dominadas polo suahili, que asumiu a maioría das funcións dos dominios públicos. O suahili converteuse na única lingua vehicular do ensino primario desde a nacionalización de todas as escolas primarias polo goberno de 1964 [...]. Así, a comezos dos setenta, as linguas autóctonas quedaran reducidas ao uso cultural e familiar. O uso limitado das linguas autóctonas non só afectou a súa adquisición efectiva por parte das xeracións máis novas, senón que tamén xerou actitudes negativas cara a elas. Como consecuencia, moitas destas linguas están a avanzar cara á súa desaparición (Batibo, 2000, p. 11).

É importante lembrar que en África coexistiron dous modelos de colonización no tocante á política lingüística. $\mathrm{O}$ coñecido como "xermánico», seguido basicamente por británicos e alemáns e baseado de xeito explícito, polo menos no caso dos primeiros, no convencemento de que o coñecemento da lingua inglesa non era accesible para a poboación autóctona e que por iso se tiña que limitar a unha elite -os «intérpretes»-, que tería que facer de intermediaria entre a poboación colonizada e a metrópole. O outro procedemento, o "románico», aplicado por franceses, portugueses e españois, seguindo o modelo do Imperio Romano, parte da consideración dos territorios de ultramar como "provincias» onde a única lingua é a oficial do Estado. Cómpre dicir que, nos seus resultados, ambos os dous modelos non mostran moitas diferenzas, dado que, sexa cal 
for o colonizador, a lingua colonial -e en moitos casos oficial- converteuse na lingua dunha elite e nun instrumento que, aínda que foi imprescindible para a mobilidade social, non está ao alcance de todos. Mesmo nos casos de colonización belga, que na Administración adoptaba o modelo románico e no ensino o xermánico, non se diferencia moito nos resultados. Por outro lado, a esperanza que podería supoñer a preservación da diversidade lingüística é contrarrestada polos prexuízos contra as linguas africanas:

En primeiro lugar, os dous problemas lingüísticos máis importantes comúns á meirande parte dos Estados africanos son: a) o papel das linguas do poder en África -xeralmente inglés, francés e portugués- e a falta dunha competencia suficiente nestas linguas por parte da maioría da poboación africana; e b) o pouco aprecio que os falantes de linguas africanas adoitan ter polas súas propias linguas [...] e as dificultades das linguas ex-coloniais para desenvolvérense educativa, económica, social e politicamente. Xa que logo, estas linguas atrancan o acceso efectivo á información e a participación nos procesos e na toma de decisións educativos, económicos e políticos. Por outra banda, a asombrosa preferencia do inglés, o francés e o portugués como linguas de aprendizaxe e ensino primario e secundario entre as comunidades africanas indica que, en xeral, os africanos consideran as súas linguas menos aptas para os usos formais (Vic Webb e Kembo-Sure, 2000).

Para rematar este percorrido pola morte das linguas, cabe mencionar Europa, continente onde o proceso xa está practicamente consumado e que, despois de exportar os modelos de exterminio de linguas que desenvolvera no seu territorio previamente, agora quere reivindicar a súa «diversidade» oficial. Talvez se deba ter presente que, do mesmo xeito que Europa difundiu os seus prexuízos anteriormente, agora pretende espallar os seus modelos de lingua -creación de estándares, desenvolvemento de sistemas de escritura, recoñecemento oficial, etc. Quizais, da experiencia histórica poderiamos extraer a conclusión de que, igual que se exportaron os procedementos de exterminio de linguas, tamén se fixo así coas ideoloxías que os sustentan, ás veces con elementos tan aparentemente inocuos como o propio concepto de lingua ou este evolucionismo do século XXI que nos continúa facendo crer que o que é bo para nós ten que ser bo para todo o mundo. 
Tanto o desenvolvemento histórico como o xeográfico do proceso de homoxeneización lingüística poden alimentar a idea de que estamos diante dun proceso imparable e incontrolable. Malia que é obvio que a solución resulta máis difícil, o feito de lembrar as causas da morte das linguas pódenos axudar a entender cara a onde deberiamos dirixir os nosos esforzos. Agás os casos de desaparición das linguas pola morte da comunidade como consecuencia de catástrofes naturais ou de xenocidio, a morte das linguas ten dous eixes cuxa alteración supón que a recuperación sexa moi difícil: o cambio da relación da comunidade co territorio e a interrupción da transmisión interxeracional.

A relación entre a lingua e mais o territorio é cuestionada acotío, pero se non existise ninguén pensaría, cando se trata de facer desaparecer unha lingua, en forzar o desprazamento dos falantes. As reservas creadas para os amerindios nos Estados Unidos de América, as vilas artificiais de Siberia, os movementos de persoas co obxectivo de mesturar falantes de linguas diferentes, etc. mostran claramente que a relación entre lingua e territorio é máis que evidente para todos os que queren eliminar a diferenza. Tal e como o explica Wurm referíndose a Maluku:

Das cento dúas linguas da zona de Maluku, once desapareceron e vinte e catro están ameazadas en maior ou menor medida. A causa principal desta extinción e situación de perigo foi e segue a ser a presión exercida polo indonesio, que fai que linguas con moitos falantes cheguen a estar ameazadas, como a lingua aluna malaio-polinesia da illa de Seram, que conta con máis de doce mil falantes. Isto é moito nunha zona onde a maioría das linguas teñen apenas uns poucos centos de falantes e outras uns poucos milleiros. Algunhas linguas sucumbiron ou quedaron en perigo debido a circunstancias particulares. Por exemplo, a grande illa de Buru é empregada para deportar delincuentes, o que provocou a desaparición dalgunhas pequenas comunidades lingüísticas; outras foron trasladadas polas autoridades indonesias a zonas moi afastadas da súa terra orixinaria, normalmente con desastrosas consecuencias. Así, os falantes da lingua nila malaio-polinesia que vivían nunha illa volcánica do extremo sur de Maluku foron trasladados polas autoridades indonesias á zona centro-sur da grande illa de Seram, a illa principal de Maluku Central (Wurm, 2003, p. 23).

Por outra banda, o feito de que non se poida nin propoñer salvar o ainu en Europa, ou o síux no deserto do Sahara ou o lardil en Indonesia, xa mostra que 
entre lingua e territorio algunha relación ten que haber. E se non se aborda esta cuestión nos proxectos de planificación lingüística, a recuperación non pode ser máis que un proceso artificial e, xa que logo, abocado ao fracaso.

A interrupción da transmisión interxeracional é o punto clave do proceso, o momento a partir do que a recuperación xa é moi difícil, se non imposible, e, de calquera xeito, o momento en que a lingua entra en fase de decadencia. A diferenza coa alteración da relación da comunidade co territorio é que, se nun caso nos atopamos con factores xeralmente externos, cando alguén interrompe a transmisión toma aparentemente unha decisión individual, íntima, e este feito agocha moitas veces as enormes presións a que son sometidos os falantes para que abandonen a lingua e mesmo as contradicións que vive quen toma esta decisión, como di Marianne Mithum:

Os falantes destas linguas e os seus descendentes son moi conscientes do que pode supoñer a perda dunha lingua [...]. Cando unha lingua desaparece, tamén o poden facer os aspectos máis íntimos dunha cultura: modos fundamentais de organizar a experiencia en conceptos, de asociar ideas e de relacionarse con outras persoas. Tamén adoitan perderse os xéneros máis conscientes da oralidade: ritos tradicionais, oratoria, mitos, lendas e mesmo o humor. Moitos falantes comentan que cando falan noutra lingua din cousas diferentes e mesmo teñen pensamentos distintos (Mithun, 1998).

Os sentimentos destes individuos seguramente son moi próximos aos que describe Larreula:

Eu mesmo, na miña recollida de testemuños de dor de lingua, no ano 1976 falei en Perpiñán cun home vello que á miña pregunta de por que non lles falara en catalán aos seus fillos explicoume que, de mozo, lle tocou facer o servizo militar no norte de Francia, e que alí, por mor das súas dificultades para expresarse correctamente en francés e do seu exótico acento meridional, foi o albo das mofas dos oficiais e de todos os seus compañeiros, que, como alá era habitual, para burlárense del chamábanlle «l'espagnol». As constantes humillacións e mesmo bromas crueis que recibiu durante aquela experiencia fixérano sufrir tanto, que desde ese momento prometeu que, cando tivese un fillo, nunca lle falaría en catalán, porque así, sendo francés de verdade, podería ir por todo o mundo, ninguén o humillaría e non tería que sufrir todo o que el sufrira (Larreula, 2004). 
A interrupción da transmisión pode acadarse tamén con outros procedementos que teñen pouco que ver coa vontade dos falantes. Desde finais do século XIX ata ben entrado o XX, varios gobernos levaron a cabo unha práctica terrible, que consistía en secuestrar os nenos das comunidades indíxenas para afastalos da súa cultura e lingua tradicionais. Como lembran Blokland e Hasselblatt, no caso do mansi:

Entre os anos cincuenta e sesenta atopáronse petróleo e gas natural na Siberia Occidental. A explotación destes recursos causoulle e aínda lle causa prexuízos considerables ao modo de vida tradicional mansi: nos anos sesenta arrasáronse seis millóns de hectáreas do hábitat natural do reno e contamináronse duascentas vinte mil hectáreas de ríos e lagos. Os oleodutos impiden que os renos se movan con liberdade e producen verteduras de petróleo á terra. As familias mansi foron concentradas en sovkozes e os seus fillos foron enviados a internados onde, tras o primeiro ano, só se fala ruso. $\mathrm{O}$ alcoholismo aumentou incriblemente e a esperanza de vida media sitúase entre os corenta e os corenta e cinco anos (Blokland e Hasselblatt, 2003, p. 127).

Aikhenvald fai unha descrición parecida, neste caso do Brasil:

Cando os misioneiros salesianos se estableceron na zona a principios dos anos vinte, impuxéronlles aos indios a escolarización ao estilo occidental, obrigando os nenos a asistiren a internados onde os facían falar só unha lingua do territorio, o tucano. O propósito dos salesianos era «civilizar» os indios. Isto non só supoñía convertelos en «bos cristiáns». Os salesianos tamén vían o multilingüismo tradicional deste territorio como un costume «pagán» e esforzáronse para que os indios fosen monolingües «coma todas as demais persoas civilizadas do mundo». O tucano foi elixido por ser a lingua maioritaria en número de falantes. Os misioneiros salesianos tamén practicaron o traslado forzoso de asentamentos indíxenas a lugares máis próximos ás misións -onde resultaba máis fácil controlar os indios- e a concentración de distintos asentamentos, eliminando así o sistema tradicional de casas longas de tribos e introducindo as casas unifamiliares de estilo europeo. Outro motivo da desintegración do multilingüismo tradicional foi a ruptura da relación ancestral entre o pai e mais o fillo. Dada a necesidade de cartos, todos os homes sans e fortes ían traballar para os brasileiros, por exemplo na recollida do lixo ou na minaría do ouro, polo que os nenos tiñan moito menos contacto coa lingua dos seus 
pais. Deste xeito, estendéronse o tucano e, en menor medida, outras linguas tucano orientais, en detrimento do tariana (Aikhenvald, 2002, p. 26).

Este procedemento, que se realizou de xeito sistemático en Australia, Siberia, Canadá e nos Estados Unidos de América, combina de feito os dous eixes que mencionamos: desprázase os falantes e interrómpese a transmisión. Moitas vítimas deste procedemento reclamáronlles aos gobernos respectivos polos danos inflixidos, por convertelos en estranxeiros para a súa propia familia, por furtarlles o código de comunicación co seu ámbito. Pero a eficacia deste sistema debería facernos tomar conciencia de que a recuperación non é só un proceso de recuperación da lingua, senón de restitución da propia historia, feito bastante difícil cando se chega á situación que describe Dalby sobre California:

$\mathrm{Na}$ actualidade, os poucos falantes nativos que quedan das linguas de California pertencen, na linguaxe politicamente correcta, a un grupo menos favorecido. Son favorecidos no tocante a coñecementos, pero desfavorecidos social e economicamente. Por que? De nenos, estas poucas persoas tiñan un contacto excepcionalmente intenso coas súas linguas, e isto porque as súas familias conseguiron mantelos afastados dos internados ou porque lograron escapar destes o antes posible, ou ben porque vivían con avós que non falaban palabra de inglés. Os pais de agora si asistiron a internados e por suposto falaron inglés. Por desgraza, estes superviventes probablemente non lles poden transmitir a súa lingua aos seus fillos e, se poden, non teñen a motivación necesaria para facelo. Practicamente ningún deles casaría cun home ou cunha muller que fale a súa lingua: haberá moi poucas persoas no seu ámbito que falen a súa lingua. E mesmo os que casasen cun falante doutra lingua amerindia terían o inglés como lingua familiar por ser a alternativa máis práctica. En moitos casos «simplemente non quedaría ninguén no mundo con quen falar» a súa lingua materna. Ademais, despois do trato recibido na escola, algunhas persoas decidiron conscientemente non facer pasar os seus fillos polo mesmo martirio [...] pero, dada a falta de contexto, a perda de uso e a omnipresencia do inglés, aínda que decidisen tentar transmitir a súa lingua, sería para eles sumamente difícil facelo (Dalby, 2002, p. 239-240).

Situacións coma a de California ilustran bastante ben as dificultades ás que se enfronta calquera proceso de recuperación, especialmente cando se ten 
que basear nunha comunidade que maioritariamente perdeu a súa lingua. Hai poucos procesos que tivesen éxito como para permitir o desenvolvemento de modelos de recuperación, pero hai suficientes como para decatarse de que os modelos de preservación que seguen os patróns occidentais non garanten o éxito. O cambio de status, por exemplo, non foi útil na revitalización do irlandés, tampouco é garantía de nada no caso do guaraní e non parece que tivese efectos destacables nas linguas bantú que son oficiais en Sudáfrica. Non podemos esquecer que, en moitas ocasións, a declaración de oficialidade é o mellor pretexto para non ocuparse da revitalización. Outro dos aspectos que cómpre ter en conta é o da escrita. Durante moitos anos e en moitos casos creuse que o desenvolvemento de estándares e sistemas de escrita era sinónimo de garantía de supervivencia. De feito, nalgúns casos pode ser inútil e ata contraproducente, como din Blokalnd e Haselblatt citando a Nikolaeva:

Non todos os especialistas opinan que a alfabetización é necesariamente boa e un indicador importante de desenvolvemento cultural: ao introducirmos a competencia escrita nunha sociedade como esta -a comunidade ob-ugria, $\mathrm{RB}-\mathrm{CH}-$, menosprezamos os seus modos ancestrais de transmisión da información, eliminamos os tons de sacralidade que puidesen existir nas tradicións orais e, no canto de preservarmos a cultura tradicional, só conseguimos difundir unha nova e envilecida (Blokland e Hasselblatt, 2003, p. 111) (Nikolaeva 1995, p. 127).

Ou como di Xamanichna, un poeta totonaco: «Moitos indíxenas néganse a aprender a ler. Por que? Porque saben que lles ensinarán nunha linguaxe que non é a súa e, en consecuencia, saben que non aprenderán e prefiren ser como son» (León-Portilla, 1992, p. 23).

A morte das linguas ponnos diante moitos retos. Un dos fundamentais é xustamente a aceptación da diferenza, porque non podemos agardar que as comunidades preserven as linguas se o custo para facéreno é a marxinación e se as únicas linguas ás que se lles dá valor son as «lingüicidas». Cando todo o mundo sexa recoñecido polo que é e non polo que incorporou dos outros, daquela a revitalización das linguas comezará a ser posible. Agardemos que non sexa demasiado tarde. 


\section{BiBLIOGRAFÍA}

AikHenvald, A.: «Traditional multilingualism and language endangerment», en M. BradleY e M. BRADLEY (ed.): Language Endangerment and Language Maintenance, Curzon, London, 2002.

Austin, P. K. e A. Simpson (ed.): Endangered Languages, Helmut Buske Verlag, Hamburg, 2007.

Batibo, H.: "The Linguistic Situation of Tanzania», en K. KaHigI, Y. KiHOrE e M. Mous (ed.): Lugha za Tanzania/Languages of Tanzania, CNWS Publications, Universiteit Leiden, 2000.

Blokland, R. e C. HasselblatT: "The endangered Uralic languages», en M. Janse e S. Tol (ed.): Language death and language maintenance. Theoretical, practical and descriptive approaches, John Benjamins, Amsterdam, 2003.

Bradley, D. e M. Bradley (ed.): Language Endangerment and Language Maintenance, Curzon, London, 2002.

Brenzinger, M. (ed.): Language Death. Factual and Theoretical Explorations with Special Reference to East Africa, Mouton de Gruyter, Berlin, 1992.

Brenzinger, M. (ed.): Language Diversity Endangered, Mouton de Gruyter, Berlin, 2007.

Comellas, P.: Contra l’imperialisme lingüistic, Eds. la Campana, Barcelona, 2006.

DAlBY, A.: Language in danger. How language loss threatens our future, Allen Lane, The Penguin Books, 2002.

DimmendaAl, G.: «Language contraction», en M. BrenZinger (ed.): Endangered Languages in Africa, Rüdiger Köppe Verlag, Köln, 1998.

DORIAN, N. C.: «Grammatical change in a dying dialect», Language, 49 (1973), p. 413-438.

DORIAN, N. C.: "The problem of the semi-speaker in language death", Linguistics, 191 (1977).

Dorian, N. C. (ed.): Investigating obsolescence. Studies in language contraction and death, Cambridge University Press, 1987.

DressLer, W.: «La mort de les llengües», Limits, 3 (1987), Ed. Empúries, Barcelona, p. 87-99.

Duchène, A. e M. Heller (ed.): Discourses of Endangerment, Continuum, London, 2007.

Fishman, J. A.: Reversing Language Shift, Multilingual Matters, 1991.

Fishman, J. A.: "On the limits of ethnolinguistic democracy», en T. SKUTNABb-Kangas e R. PHILLIPSON (ed.): Linguistic Human Rights. Overcoming Linguistic Discrimination, Mouton de Gruyter, Berlin, 1994.

Fishman, J. A. (ed.): Can threatened languages be saved?, Multilingual Matters, 2001.

Grenoble, L. A. e L. J. WhaleY: Endangered Languages. Current Issues and Future Prospects, Cambridge University Press, 1998.

Grenoble, L. A. e L. J. Whaley: Saving languages. An Introduction to language revitalization, Cambridge University Press, 2006.

HaArmann, H.: Language in Ethnicity. A View of basic Ecological Relations, Mouton de Gruyter, Berlin, 1986.

HaArmann, H.: Babylonische Welt. Geschichte und Zukunft der Sprachen, Campus Verlag, Frankfurt/New York, 2001.

Hagège, C.: Halte à la mort des langues, Odile Jacob, Paris. Tradución española: No a la muerte de las lenguas, Paidós, Barcelona, 2000.

Harrison, K. D.: When languages die. The Extinction of the World's Languages and the Erosion of Human Knowledge, Oxford University Press, 2007. 
Hinton, L. e K. Hale (ed.): The Green Book of Language Revitalization in Practice, Academic Press, San Diego, 2001.

JANSE, M. e S. TOL (ed.): Language death and language maintenance. Theoretical, practical and descriptive approaches, John Benjamins, Amsterdam, 2003.

JUNYENT, M. C.: Vida i mort de les llengües, Ed. Empúries, Barcelona, 1992.

JunYent, M. C.: Contra la planificació, Ed. Empúries, Barcelona, 1998.

Krauss, M.: «The world's languages in crisis», Language, 68 (1992) p. 4-10.

Larreula, E.: Dolor de llengua, Edicións 3 e 4, Valencia, 2004.

LeE, T. e D. McLaughlin: «Reversing Navajo Language Shift, Revisited», en J. A. Fishman (ed.): Can threatened languages be saved?, Multilingual Matters, 2001.

LEÓN-Portilla, M.: Literaturas indígenas de México, Mapfre, Madrid, 1991.

Mithun, M.: «The significance of diversity in language endangerment and maintenance», en L. A. GRENOBLE e L. J. Whaley (ed.): Endangered Languages. Current Issues and Future Prospects, Cambridge University Press, 1998.

Nettle, D. e S. Romain: Vanishing Voices. The extinction of the world's languages, Oxford University Press, 2000.

Robins, R. H. e E. M. Uhlenbeck (ed.): Endangered languages, Berg, Oxford/New York, 1991.

TASAKU TSUNODA: Language Endangerment and Language Revitalization. An Introduction, Mouton de Gruyter, Berlin, 2006.

Thomason, S. G.: Language Contact. An Introduction, Edinburgh University Press, 2002.

TsITSIPIS, L. D.: A Linguistic Anthropology of Praxis and Language Shift. Arvanitika (Albanian) and Greek in Contact, Oxford University Press, 1998.

Vic Webb e Kembo-Sure (ed.): African Voices. An Introduction to the Languages and Linguistics of Africa, Oxford University Press, 2000.

WURM, S.: «Language in the Greater Pacific Area», en M. JANSE e S. TOL (ed.): Language death and language maintenance. Theoretical, practical and descriptive approaches, John Benjamins, Amsterdam, 2003. 